\title{
Effects of Partial Substitution of Lean Meat with Pork Backfat or Canola Oil on Sensory Properties of Korean Traditional Meat Patties (Tteokgalbi)
}

\author{
Bue-Young Imm ${ }^{1}$, Chung Hwan $\mathrm{Kim}^{1}$, and Jee-Young Imm²,* \\ ${ }^{1}$ Corporate Technology Office, Pulmuone Co., Ltd., Seoul 120-749, Korea \\ ${ }^{2}$ Department of Foods and Nutrition, Kookmin University, Seoul 136-702, Korea
}

\begin{abstract}
Korean traditional meat patties (Tteokgalbi) were prepared by replacing part of the lean meat content with either pork backfat or canola oil and the effect of substitution on sensory quality of the meat patties was investigated. Compared to the control patties, pork-loin Tteokgalbi with $10 \%$ pork backfat or $10 \%$ canola oil had significantly higher overall acceptability and higher perceived intensity of meat flavor, sweetness, umami, and oiliness. The pork-loin patties containing $10 \%$ fat also had lower perceived firmness, toughness, and chalkiness of than the control Tteokgalbi. The chicken breast Tteokgalbi with $10 \%$ canola oil had the lowest perceived firmness and chalkiness (control > pork backfat $>$ canola oil). No significant difference was noted in the overall acceptability of chicken breast patties with $10 \%$ pork backfat and those with $10 \%$ canola oil. These results indicate that substituting $10 \%$ of lean meat of Tteokgalbi with fat improved the sensory acceptability of the product for Korean customers regardless of the lean meat and/or fat source used in the patties. Lean meat patties formulated with a limited amount of vegetable oil such as canola oil can be a healthy option for Korean consumers by providing desirable fatty acid profiles without sacrificing sensory quality of the product.
\end{abstract}

Keywords: meat patty, pork loin, chicken breast, canola oil, Korean consumers

\section{Introduction}

Reduction of fat in meat products is of special interest to the meat industry because of health concerns. However, fat content significantly affects the sensory properties and consumer acceptability of commercial meat products. The presence of fats and oils contribute to the surface appearance of meat products by providing sheen, gloss, and color whereas reducing fat content often leads to dark coloration and a rubbery less juicy texture (Mallika, et al., 2009; Myers et al., 2009). Partial replacement of meat fat with vegetable oils is a possible approach for producing healthier meat products because replacing animal fat with vegetable oils alters fatty acid profiles and improves nutritional quality of meat products. However, limited and somewhat inconsistent information is available concerning the effects of fat content on the sensory

*Corresponding author: Jee-Young Imm, Department of Foods and Nutrition, Kookmin University, Seoul 136-702, Korea. Tel: +82-2-910-4772; Fax: +82-2-910-5249, E-mail: jyimm@ kookmin.ac.kr quality of meat products (Ansorena and Astiasaran, 2004; Severini, et al., 2003).

There is a strong preference among Korean consumers for high fat cuts of pork such as pork belly and Boston butt (Oh and See, 2012) and this preference may affect the sensory acceptability of meat products with different levels of fat. Korean traditional meat patties, including Tteokgalbi, Neobiani and Donggrantteng are made of a mixture of meat, fat, tofu, vegetables, and seasonings and these patties are popular commercial meat products.

In this study, pork and chicken tteokgalbi meat patties were prepared by replacing part of the lean meat content with either pork backfat or canola oil and effects of substitution on sensory quality of the patties were evaluated.

\section{Material and Methods}

\section{Manufacture of Tteokgalbi meat patties}

Tteokgalbi meat patties were prepared using the following: $50 \%$ lean meat (pork loin or chicken breast) for the control, $28 \%$ tofu, 0 or $10 \%$ fat (pork fat or canola oil) and $22 \%$ seasoning mix. The seasoning mix consists of 
5\% shiitake mushroom, $5 \%$ green onion, $3 \%$ garlic, $3.5 \%$ sugar, $4 \%$ soy sauce, $1 \%$ sesame oil, and $0.5 \%$ potato starch. In case of treatment samples $10 \%$ of lean meat was substituted with pork backfat or canola oil and other formulation was the same. Thus, total six different types of Tteokgalbi based on lean meat source (pork loin or chicken breast), fat substitution ( 0 or $10 \%)$, and fat source (pork backfat or canola oil) were prepared. All ingredients were minced in a cutter to produce homogeneous batter. No artificial flavors, colors, and/or monosodium glutamate (MSG) was used. Batters were packed in aluminum trays and cut into $30 \pm 5 \mathrm{~g}$ mini patties $(5 \mathrm{~cm} \times 5$ $\mathrm{cm} \times 1 \mathrm{~cm}$ ) and were frozen at $-40^{\circ} \mathrm{C}$. The frozen patties were stored for three days until use for the sensory test. The frozen patties were baked in a pre-heated $180^{\circ} \mathrm{C}$ oven for $15 \mathrm{~min}$ before the sensory evaluation. All the samples were manufactured by Pulmuone Co. Ltd. in Seoul, Korea.

\section{Sensory tests}

The perceived intensity of sensory attributes of the meat patties was measured on a 9-point scale anchored with 1 (very weak) to 9 (very strong). Overall acceptability of the meat patties was measured using a 9-point hedonic scale ranging from 1 (dislike very much) to 9 (like very much). Fifty female consumers (30 to 49 years old) who purchased meat patties more than twice a month were recruited for participation in the sensory test through an online announcement. The purpose of the sensory test in this study was to analyze consumer acceptability and perceived intensities of important sensory attributes of Tteokalbi samples. The sensory tests were conducted on two sets of samples. The first set consisted of control, pork loin patties with $10 \%$ pork backfat, and pork loin patties with $10 \%$ canola oil, while the second set consisted of control, chicken breast patties with $10 \%$ pork backfat, and chicken breast patties with $10 \%$ canola oil. Samples in each set were presented side-by-side and were served in paper cups coded with three-digit random numbers. There was a $10 \mathrm{~min}$ break between the testing of each set of samples.

\section{Moisture and fat content of meat patties}

The moisture content of the patties was determined using the AOAC method (AOAC, 2000) and fat content was determined by Soxhlet method. All quantifications were performed in triplicate.

\section{Statistical analysis}

Statistical analyses were performed using Minitab 14.0 (Minitab Inc., 2000). Differences among three samples within each set were analyzed by one-way ANOVA with a significance level of 0.05 and the means were compared using Fisher's LSD multiple comparison test.

\section{Results and Discussion}

\section{Effect of pork backfat and canola oil substitution on sensory properties of Tteokgalbi}

Table 1 shows the moisture and fat content of Tteokgalbi produced from either pork loin or chicken breast. Control patties had a significantly lower fat content than the patties with pork backfat and canola oil but there was no significant difference in fat content between backfat and canola oil substituted patties. Compared to the control patties, pork-loin Tteokgalbi with $10 \%$ pork backfat or $10 \%$ canola oil had significantly higher overall acceptability and higher perceived intensities of meat flavor, sweetness, umami, and oiliness (Fig. 1A). The pork loin patties containing $10 \%$ fat also had lower perceived firmness, toughness, and chalkiness of than the control Tteokgalbi. There was no significant difference between the perceived saltiness, sweetness, umami, meat flavor, meat texture, toughness, and/or firmness of the pork loin patties with pork fat and those with canola oil.

The sensory profile of the Tteokgalbi prepared with chicken breast was similar to that of pork-loin Tteokgalbi (Fig. 1B). The chicken breast Tteokgalbi with 10\% canola oil had the lowest perceived firmness and chalkiness (control $>$ pork backfat $>$ canola oil) $(p<0.05)$. No significant difference was noted in the overall acceptability of chicken breast patties with $10 \%$ pork backfat and those with $10 \%$ canola oil.

Table 1. Moisture and fat content of Korean traditional meat patties (Tteokgalbi)

\begin{tabular}{ccccccc}
\hline \hline \multirow{2}{*}{ Meat patty } & \multicolumn{3}{c}{ Moisture (\%) } & \multicolumn{3}{c}{ Fat (\%) } \\
\cline { 2 - 7 } & Control & Porkfat & Canola & Control & Porkfat & Canola \\
\hline Pork loin & $70.5 \pm 0.6^{\mathrm{a}}$ & $63.3 \pm 0.5^{\mathrm{b}}$ & $62.5 \pm 0.9^{\mathrm{b}}$ & $4.3 \pm 0.6^{\mathrm{b}}$ & $15.6 \pm 0.6^{\mathrm{a}}$ & $14.6 \pm 0.7^{\mathrm{a}}$ \\
Chicken breast & $70.8 \pm 0.2^{\mathrm{a}}$ & $63.8 \pm 1.2^{\mathrm{b}}$ & $63.4 \pm 0.6^{\mathrm{b}}$ & $3.9 \pm 0.2^{\mathrm{b}}$ & $13.9 \pm 0.5^{\mathrm{a}}$ & $13.5 \pm 0.3^{\mathrm{a}}$ \\
\hline
\end{tabular}

Tteokgalbi patties were formulated either pork loin or chicken breast and $10 \%(\mathrm{w} / \mathrm{w})$ of the meat source was substituted with either pork backfat or canola oil. Control patties contained lean meat with no fat substitution. The values with different superscript letters a-b indicates significant difference $(p<0.05)$ within same row. 
(A)

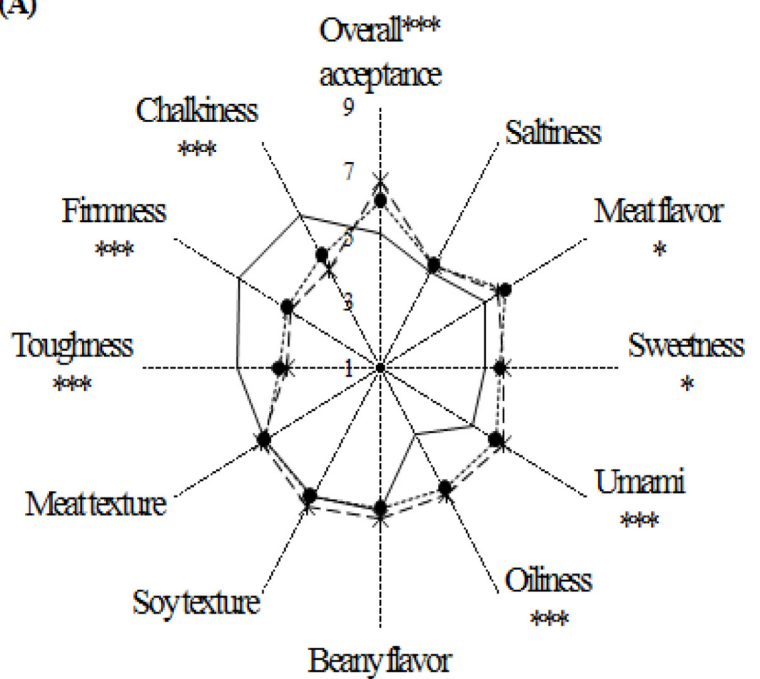

(B)

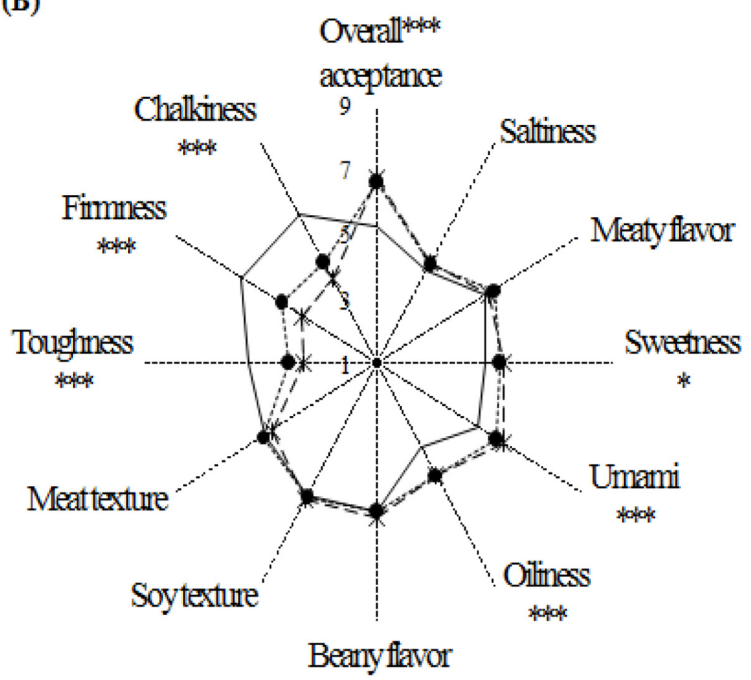

Control $\quad-\cdots \cdot-$ Porkfat $\quad-*$ - Canolaoil

\begin{tabular}{cccccccccc}
\hline & & $\begin{array}{c}\text { Overall } \\
\text { acceptance }\end{array}$ & $\begin{array}{c}\text { Meat } \\
\text { flavor }\end{array}$ & Sweetness & Umami & Oiliness & Toughness & Firmness & Chalkiness \\
\hline \multirow{2}{*}{$\begin{array}{c}\text { (A) } \\
\text { Pork loin }\end{array}$} & Control & $5.12^{\mathrm{a}}$ & $5.06^{\mathrm{a}}$ & $4.51^{\mathrm{a}}$ & $4.60^{\mathrm{a}}$ & $3.39^{\mathrm{a}}$ & $5.78^{\mathrm{a}}$ & $6.48^{\mathrm{a}}$ & $6.40^{\mathrm{a}}$ \\
& Pork fat & $6.08^{\mathrm{b}}$ & $5.82^{\mathrm{ab}}$ & $5.00^{\mathrm{ab}}$ & $5.50^{\mathrm{b}}$ & $5.32^{\mathrm{b}}$ & $4.34^{\mathrm{b}}$ & $4.64^{\mathrm{b}}$ & $4.94^{\mathrm{b}}$ \\
& Canola oil & $6.73^{\mathrm{c}}$ & $5.59^{\mathrm{b}}$ & $5.17^{\mathrm{b}}$ & $5.76^{\mathrm{b}}$ & $5.49^{\mathrm{c}}$ & $4.10^{\mathrm{b}}$ & $4.47^{\mathrm{b}}$ & $4.43^{\mathrm{c}}$ \\
\hline \multirow{3}{*}{$\begin{array}{c}\text { (B) } \\
\text { Chicken breast }\end{array}$} & Control & $5.29^{\mathrm{a}}$ & & $4.67^{\mathrm{a}}$ & $4.96^{\mathrm{a}}$ & $4.00^{\mathrm{a}}$ & $5.41^{\mathrm{a}}$ & $6.35^{\mathrm{a}}$ & $6.33^{\mathrm{a}}$ \\
& Pork fat & $6.62^{\mathrm{b}}$ & & $5.16^{\mathrm{ab}}$ & $5.66^{\mathrm{b}}$ & $4.96^{\mathrm{b}}$ & $4.00^{\mathrm{b}}$ & $4.80^{\mathrm{b}}$ & $4.62^{\mathrm{b}}$ \\
& Canola oil & $6.74^{\mathrm{b}}$ & & $5.30^{\mathrm{b}}$ & $5.94^{\mathrm{b}}$ & $5.00^{\mathrm{b}}$ & $3.50^{\mathrm{b}}$ & $3.98^{\mathrm{c}}$ & $4.02^{\mathrm{c}}$ \\
\hline
\end{tabular}

Fig. 1. Perceived intensity of sensory attributes and overall acceptability of lean meat Tteokgalbi patties prepared from (A) pork loin or (B) chicken breast. Tteokgalbi meat patties were prepared using the following: $50 \%$ lean meat (pork loin or chicken breast) for the control, $28 \%$ tofu, $0 \sim 10 \%$ fat (pork fat or canola oil) and $22 \%$ seasoning mix (soy sauce, sugar, sesame oil, shiitake mushroom and potato starch). In case of treatment samples $10 \%$ of lean meat was substituted with pork backfat or canola oil and other formulation was the same. $\left({ }^{*} p<0.05,{ }^{* *} p<0.01,{ }^{* * *} p<0.001\right)$.

These results indicate that substituting $10 \%$ of lean meat of Tteokgalbi with fat improved the sensory acceptability of the product for Korean customers regardless of the lean meat and/or fat source used in the patties. Korean consumers strongly prefer light red, high fat content and no-drip pork (Ngapo et al., 2007; Vonada et al., 2000). The preference of high fat portion pork was also demonstrated by the study for Korean consumers' choice of pork chops using image analysis (Cho et al., 2006).

Canola oil contains high concentrations of unsaturated fatty acids (55\% oleic, $25 \%$ linoleic and $10 \%$ a-linolenic acids) and is widely used in salads and cooking. In hyperlipidemic patients, the effect of canola oil on the lipoprotein profile and glucose tolerance were similar to those of olive oil (Nydahl et al., 1995). Replacing saturated fatty acid with canola or safflower oil also significantly decreased in LDL-cholesterol in healthy men even when the total fat content remained constant (Wardlaw et al., 1991). From the perspective of applications, the incorporating of canola oil or pre-emulsified canola oil into comminuted meat products improved both product yield and texture (Youssef and Barbut, 2011).

\section{Conclusions}

Fats and oils generally improve mouthfeel and increase tenderness, juiciness, and chewiness of meat products. We found that substituting lean meat with an appropriate amount of fat significantly improved consumer acceptance of meat patties. Canola oil, specifically, serve as a fat source without sacrificing acceptability, which suggests that formulating lean meat patties with a limited amount of vegetable oil can be a healthy option for Korean consumers. 


\section{Acknowledgements}

This study was financially supported by Pulmuone Co., Ltd. to examine effects of substitution with pork backfat and canola oil on the Korean consumers' acceptability of meat patties.

\section{References}

1. Ansorena, D. and Astiasaran, I. (2004) The use of linseed oil improves nutritional quality of the lipid fraction of dry-fermented sausages. Food Chem. 87, 69-74.

2. AOAC (2000) Official methods of analysis. $17^{\text {th }}$ ed., Association of Official Analytical Chemists. Gaithersburg, MD.

3. Cho, S., Park, B., Ngapo, T., Kim J., Dransfield, E., Hwang, I., and Lee, J. (2007) Effect of meat appearance on south Korean consumers' choice of pork chops determined by image methodology. J. Sens. Stud. 22, 99-114.

4. Mallika, E. N., Prabhakar, K., and Reddy, P. M. (2009) Low fat meat products - An overview. Vet. World 2, 364-366.

5. Myers, A. J., Scramlin, S. M., Dilger, A. C., Souza, C. M., McKeith, F. K., and Killefer, J. (2009) Contribution of lean, fat, muscle color and degree of doneness to pork and beef species flavor. Meat Sci. 82, 59-63.

6. Ngapo, T. M., Martin, J. F., and Dransfield, E. (2007) Inter- national preferences for pork appearance: I. Consumer choices. Food Qual. Prefer. 18, 26-36.

7. Nydahl, M., Gustafasson, I. B., Ohrvall, M., and Vessby, B. (1995) Similar effects of rapeseed oil (canola oil) and olive oil in a lipid lowering diet for patients with hyperlipoproteinemia. J. Am. Coll. Nutr. 14, 643-651.

8. Oh, S. H. and See, M. T. (2012). Pork preference for consumers in China, Japan and South Korea. Asian-Austral. J. Anim. 25, 143-150.

9. Severini, C., Pilli, T. D., and Baiano, A. (2003) Partial substitution of park backfat with extra-virgin olive oil in salami products: effect on chemical, physical and sensorial quality. Meat Sci. 64, 323-331.

10. Vonada, M. L., Bidner, B. S., Belk, K. E., McKeith, F. K., Lloyd, W. R., O'Connor, M. E., and Smith, G. C. (2000) Quantification of pork belly and Boston butt quality attribute preferences of South Korean customers. J. Anim. Sci. 78, 2608-2614.

11. Wardlaw, G. M., Snook, J. T., Lin, M. C., Puangco, M. A., and Kwon, J. S. (1991) Serum lipid and apolipoprotein concentrations in healthy men on diets enriched in either canola or safflower oil. Am. J. Clin. Nutr. 54, 104-110.

12. Youssef, M. K. and Barbut, S. (2011) Fat reduction in comminuted meat products-effects of beef fat, regular and preemulsified canola oil. Meat Sci. 87, 356-360.

(Received 2014.6.16/Revised 2014.7.9/Accepted 2014.7.16) 